\title{
Difference, Boycotting, Infiltration----the Analysis of Attribute of the National Costumes in Nansong and Beisong Dynasty
}

\author{
Meng Li (Corresponding author) \\ Fashion\&Art Design Institute, Donghua University \\ 1882 West Yan An Road, Shanghai 200051, China \\ Tel: 86-21-6237-3968 E-mail: moniqueli@126.com
}

Bin Wang

Shanghai Institute of Visual Art

2200 Wen Xiang Road, Shanghai 201620, China

Tel: 86-21-6782-2549 E-mail: Fucy_111@yahoo.com.cn

The Research is supported by Shanghai Leading Academic Discipline Project, Project Number:B601

\begin{abstract}
The costume in Nansong and Beisong Dynasty create a style all it's own, which stands in contrast to others during the periods of Chinese feudal separatist rule. All the leader of the political powers in the Song, Liao, Xia, and Jing Dynasty launched relatively policies in order to maintain the distinguishing feature. The emperor of Song Dynasty promulgates decrees frequently to boycott the National costume in the Western Regions. But still, the exchange and mixing of distinct costumes styles could be found. The attribute and the relationship in the general progress of costume in Nansong and Beisong Dynasty would be discussed and analyzed in this article.
\end{abstract}

Keywords: Nansong and Beisong Dynasty, Costume, Race, Attribute

In the year $960 \mathrm{AD}$ Zhao Kuangyin established Beisong state, which provoked an end to the period of many local separatist regimes, namely the period of Five Dynasties and Ten Kingdoms. However, China was only partial united during Beisong period, beside Beisong, there were regimes of Liao, His-hsia, Tubo and Dali coexisted on the territory of the whole country, and after Beisong, there were Nansong struggled against Jin, and later, at the beginning of $13^{\text {th }}$ century, the newly-risen Mongolian regime destroyed His-hsia, Jin, Nansong one after another and finally brought the history of China into a period of unity. Compared with other periods of local separatist regimes in history, the Song period was special, except Song, other regimes were respectively set up by a single minority. Song and those minority regimes were coexisted for a long time and frequently contact with each other, therefore inevitably, during this period, the culture of costumes of different races exchanged and as it developed, its unique attributes revealed. This essay offered a discussion on the confliction and exchange of culture of costumes among Song, Liao, His-hsia and Jin.

\section{Difference}

\subsection{Traditional Costumes of Each Races}

Song, Liao, His-hsia and Jin were respectively set up by the races of Han, Khitan, Tangut and Jurchen, each was featured by their distinctively traditional costumes.

Except in sacrificial or other ceremonious occasions, the Emperor and officials of Song Dynasty usually wear ' $f u$ tou (made of cloth with a function similar to hat)', robes with a round-collar, loose sleeves and a belt engirdled the waist, and black leather boots. Literary men favored a high square-cube-shaped hat, which was called 'gao zhuang jin zi' and went with loose clothes in Song Dynasty. The clothes of common men were very simple, with cross collars and few made of silk in beautiful colors. Women of this period usually wore highly tied puns decorated with long combs and sometimes covered with flower-pinned hats, a popular dress called 'bei $z i$ ' and characterized by a front opening, two 
slits at two sides up to the arms and coordinated with skirts (usually pleated Figure 1) or trousers. The early 'bei $z i$ ' was short, later, it became longer and longer and finally a standard model was formed: a dress with sleeves looser than that of shirt and as long as skirt.

According to Liao shi (history of the Liao Dynasty), at an early time the Khitans were dressed in animal skin and fur (Tuotuo, 1974, p.905). During the reign of Yelüdeguang (902-942), the regulations of costumes established, stipulating the costumes of the Khitans and the Hans could coexist. The description of Khitan's traditional costumes in historical documents is indistinct; fortunately we can get some information from the figures in mural paintings of the Liao Dynasty and examples found during excavation. Men appeared in mural paintings mostly have their heads shaved or warped by scarves (Tuotuo, 1974, p.907), one common type of head shaving is to shave off all the hair but with some short hair remained on the forehead and one lock naturally fallen from each temple, or with the hair on the forehead symmetrically shaved into different shapes while the rest hair is shaved off. They are usually in round-collared tight robes with a left opening in the front and a slit at the back, small-bottomed trousers and coordinated with boots. Some boots were below the knees, some were to the thigh. (Figure 2) Women of the Liao Dynasty also had their heads shaved before they got married; while married, they usually wore their hair up in a bun and covered by a high round hat with ribbons drooped from the back. One common dress for women was a sweeping robe, with a cross collar, a left opening, narrow sleeves and a belt engirdled the waist, depicting in the mural paintings in the tombs found in Kulunqi and Balinzuoqi. (Figure 3) Open-seat pants, pantskirts and skirts with gallus were found from the tomb dated to the Liao Dynasty in Daiqintala, Xing'anmeng, Inner Mongolia, indicating it was a custom for Khitans to add gallus to pants or skirts.

The ancestor of Tanguts is Xiqiang, who used to be dressed in fur, woolen, felt and etc (Liu Xu,1975, pp.5290-5292). The hair of Xiqiang people naturally fell or braided, while the traditional hairstyle of tanguts was to make the hair at the two sides of the forehead shaped like bird's wing and the hair at back tied into two circles. (Figure.4) Tanguts began to shave head since the year 1033 AD in which a command forcing people to shave head issued by Li Yuanhao. The costumes of military officials of His-hsia had a flavor of Tanguts: a slightly spiked hat, with ribbons hung from the back; a tight-sleeved robe, with a cross collar and a belt engirdled the waist; and coordinated with a pair of boots. Women had hair tied up to peach-shaped bun and wore long tight-sleeved robes with cross collars and slits.

Compared with Khitans, fewer materials about the costumes of Jurchens were found. From historical documents we knew they preferred white. It is also recorded that men of Jurchen also had their heads shaved, but different from that of Khitan, their hair on the back of the head remained and braided into a great number of little tresses and then tied with silk threads in various colors, rich men even decorated their hair with jewelry or gold (Figure 5); While women usually had their hair braided first then tied into a roll (Yuwenmaozhao, 1986, p.552). Commonly, men had their heads wrapped with scarves, in tight-sleeved robes, with a belt engirdled the waist and black leather boots on feet; while women preferred a left-opened straight-collared shirt, with a reddish yellow ribbon engirdled the waist and coordinated with a skirt. These records were supported by the examples excavated from the tomb dated to the Jin Dynasty of the king of the Qi state found in Heilongjiang.

\subsection{Costumes of Each Race Coexisted}

Liao, His-shia and Jin were respectively established by the Khitans, Tanguts and Jurchens, however, there were other races under each regime, for example, under the regime of Liao there were the Hans, Jurchens and etc. besides the Khitans, therefore usually costumes of each races under each regime coexisted.

When minorities got strong, their regimes became stable and acquired equal standing with the Song state; they began to approach the task of establishing administrative authorities and ceremony regulations. In order to keep the features of their own costumes, various policies were made. Liao allowed costumes of different races coexisting under its regime from the beginning, stipulating the queen mother and officials of Khitan wore Khitans' traditional costumes while the emperor and official of Han wear Hans' traditional costumes (Tuotuo, 1974, p.908). Later, the costumes of the Hans were adopted by more people and in more occasions, for example, since the period of qian heng (979AD-983AD) officials of Khitan ranked higher than three grades should wear Hans' costumes, and since the year 1031AD all of the officials should wear Hans' costumes in grand ceremonial occasions (Tuotuo, 1974, p.908). The costumes of Tanguts had been greatly influenced by that of the Song Dynasty before His-shia was established. Li Deming, an emperor of His-shia, used to say that thanks to the Song state, they can be dressed in silk for thirty years. Regulations of costumes with Tanguts' distinctive ethnic characteristics was set up during the reign of Li Yuanhao, according to which, civil officials of His-shia should wear a kind of costumes quite similar to that worn by the officials in the Tang and Song Dynasties. In 1033AD, Li Yuanhao promulgated a decree forcing people to shave their heads (Wu Guangcheng and Gong Shijun, 1995, p.132), however, 'people' here only refers to tanguts, did not include people of other races. And after the third generation, Jurchens moved their capital to the south and began to wear the ceremonial costumes of the Hans (Tuotuo, 1975, p.975). 


\section{Boycotting}

Hans' culture had grown up to a certain height till the Song Dynasty, with a properly constituted system of ceremonies. The minorities more or less had been influenced by Hans' culture before they established their regimes. Liao and His-shia used to attach to the government of the Hans, Jurchen had been in contact with Song before Jin was established and this relationship didn't ended until the beginning of the $11^{\text {th }}$ century (Herbert Franke and Denis Twitchett, 1998, p.228); therefore it was inevitable for minorities to borrow ceremonial system and administrative model from the Hans. However, countries they ruled were multi-ethnic countries in which many Hans lived and occupied vast regions which used to be controlled by the Hans for a long time, therefore on the one hand they learned Hans' culture and on the other hand they had to take measures to maintain the characteristics of their own culture and sometimes they even had to take steps to against the influence of Hans' culture.

No ban made by emperors of the Liao Dynasty against costumes of the Hans or on forcing the Hans under Liao's regime to adopt Khitans' costumes had been found until now, while Jin made bans against the customs of the Hans even during its early years, for example, in November 1126AD, the commanders surrendered to the Jin government were warned by the privy council that the one who didn't be dressed as Jurchens did was considered not to be royal to the Jin government and should be severely punished, and in 1129 AD, in Marshal's hotel a ban against Hans' costumes was put in force and the one who didn't have his head shaved as Jurchens did would subject to the penalty of death (Li Xinchuan, 1992, p.432). However, as the regime became stable, bans against the Hans' costumes were gradually lifted, for example, in $1150 \mathrm{AD}$, Emperor Wanyan Liang made a law according to which people in the region of Henan under his reign could be dressed as they like. But as the influence from the Hans on Jurchen's costumes increasingly grew, governors of the Jin Dynasty retook the measures of backing Jurchens' costumes, for example, in the year 1187AD, the emperor Shizong forbade Jurchens from wearing Hans' costumes (Tuotuo, 1975, p.199). While in His-shia, wearing costumes of the Tanguts or the Hans indicated the battle between the queen mother and the emperor, when the queen mother gain the power, people wore Tanguts' costumes; when the power fell into the hands of the emperor, the costumes of the Hans revived. The system of costumes of His-shia was gradually improved during this struggle (Xie Jing, 2007, p.26).

The Song government took a firm stand on resisting the impact of the costumes of the minorities, for many times, Song promulgated bans against other races' costumes. In the year 1025, the Song government issued an order forbidding people in the capital to wear clothes with white patterns on dark brown ground or with clamp resist-dyed pattern on blue, yellow or purple ground and forbidding women from using white or brown woolens and light brown textiles for their clothes, woolens were only allowable for protecting against dust while out riding (Tuotuo, 1977, p.3575); And in 1048AD, a ban expressly against Khitans' costumes was made (Tuotuo, 1977,p.3576). In the last years of Beisong Dynasty during the reign of Huizong, bans against costumes of the minorities were frequently issued; according to incomplete statistics, three bans against Khitans' costumes were made by Huizong during this period, one was made in November 1110AD (Wu Zeng, 1979, p.387), one was made at the beginning of 1111AD (Wu Zeng, 1979, p.16) and one was made in 1117AD (Tuotuo, 1977, p.3577).In August 1163AD, the Song government promulgated another ban to forbid luxurious, bizarre costumes and costumes of the minorities (Li Zhiliang, 2005, pp.1627-1664).

It was worth notice that costumes similar to that of the minorities were also forbidden in the Song Dynasty. A funny story recorded in Zhong wu ji wen (records related to a place named zhong wu in China made by Gong Mingzhi in the Song Dynasty):a decree was promulgated by the Song government around the year 1119AD, according to which the gentry classes had to wear head bands, but the head bands were not allowed to be tied at the back of the head and fall over the shoulder because the outfit resembled that of the minorities, so the gentry classes had their head bands tied on the forehead, however, the one dressed in this way was quite similar to the lowest ranked military official 'bao $y i$ ' in the Song Dynasty. Form this story we learned that the Song government took a quite firm stand on resisting costumes of the minorities, besides costumes of the minorities, costumes similar to that of the minorities were also forbidden.

The hostile attitude of the Song government toward the costumes of the minorities had much to do with the political situation at that time. Although politically the Song government had an equal status with other regimes, militarily it was in a weak position. If the status of the emperor of Song was reluctantly accepted by the Liao government, the treaty signed by the governments of Song and Jin in 1142AD was really a shame for Song, in which Song had to admit that he is a vassal owing allegiance to the Jin government and promise to render tribute to Jin every year, and this relationship didn't terminate till the year 1164AD.

\section{Infiltration}

Although there was boycotting, as time went by, little by little the costumes of different races reacted on each other and finally a phenomena of large-scale merging occurred. The cultural exchanges among ethnic groups have always been a research subject caused concern to historians. Scholars have an early start in the researching on the influence of Hans' culture on the culture of Liao, His-shia and Jin, and have made discussion of all sides on this topic, while little attention was paid to the influence of the culture of the minorities on Hans' culture. Since the 1980s, several influential works on 
costume history have mentioned the influence of Khitans' costumes on the costumes of the Song Dynasty, but quite in a vague way. At an earlier time, Shen Congwen began to do research on the influence of Khitans' costumes on the Hans', he pointed out that Khitans' costumes even influenced the costumes of the upper classes of Beisong Dynasty (Shen Congwen, 2005, p.8). The research has deepened since the end of the 1990s. In addition, discussion was made on the topic how the Hans was reacted by the minorities in some master's and doctoral thesis on the history of the Song and Liao Dynasties, for example, Ji Nannan believed that the characters and customs of the Hans under the rule of Liao had already greatly assimilated to that of the Khitans (Ji Nannan, 2006). It should be pointed out that as to the interaction of costumes among different races during the Song period, the attention are mainly paid to the interaction of costumes between the Hans and the minorities, but in fact, the relationship of costumes among the minorities is also close, now we take 'zhan li' and 'diao dun' for example.

'Zhan li' and 'diao dun' were mentioned in the ban promulgated by the Song government in the year 1117AD. They were two reprehensive Khitans' costumes in the opinion of the Song government. ' $\mathrm{Li}$ ' is a triangle-shaped hat made of thin bamboo strips or palm fibers for keeping from the sunlight or rain, therefore, 'zhan li' could be a hat in the shape of a ' $l i$ ' but made of felt ('zhan') or lined with felt. However, no example of 'zhan li' has been found, so it is hard for us to know how it looks like and how it is made. The hat worn by the man on horse depicted in the mural painting in the tomb of Xiao Yi found in Fakuyemaotai could be 'zhan li' (Figure.6) (Wen Lihe, 1989, p.327). In fact, 'zhan li' was not particular to the Khitans, it was also adopted by the Tanguts and Jurchens. The hat worn by one of the four dancers on the lower right corner of the colored scroll painting 'Avalokitesvara' excavated from Heishuicheng, E'ji'naqi, Inner Mongolia now collected in the Hermitage Museum (St Petersburg, Russia) is in the shape of a ' $l i$ ' (Figure.7). It was recorded in the work $X u$ zi zhi tong jian (an continuation of the historical work History as a Mirror) that in the year 1131AD, five thousand riders of the Jin state in white 'zhan li' headed to the Huaihe River (Bi Yuan, 1957, p.2709). The hat worn by the soldier of the Jin State on the left of the scroll painting'Pin Jin Tu' attributed to Yang Bangji is a white 'zhan li' (Yu Hui, 1990, p.38) . 'Diao dun' may refer to different Chinese characters (Meng Yuanlao and Deng Zhicheng, 1982, p.196), according to Song shi (history of the Song Dynasty), 'diao dun' was also called 'wa ku' and only used by women (Tuotuo, 1977, p.3577). ' $W a k u$ ' means pantyhose;therefore 'diao dun' could be a costume resembling pantyhose. Similar examples had been found in the tombs dated to the Liao Dynasty in Daiqintala and Xiaojingzi and also in the tomb of the King of the Qi State dated back to the Jin Dynasty .

Here are the possible reasons why the costumes of the Khitans, Tanguts and Jurchens shared similarities: firstly, they might have learned from each other, for example, 'zhan li' and 'diao dun' perhaps used to be the costumes of the Khitans, but later the Tanguts and Jurchens borrowed because it was of practical value; secondly, the life style, the living environment of these races were similar, therefore it was possible for them to adopt same costumes. However, these need a further research.

\section{Conclusion}

According to the above arguments, the attributes of the national costumes can be briefly summed up in there words: difference, boycotting and infiltration. In the development of national costumes, these three attributes were coexisted and interacted; their relationship can be represented by the following graph: 


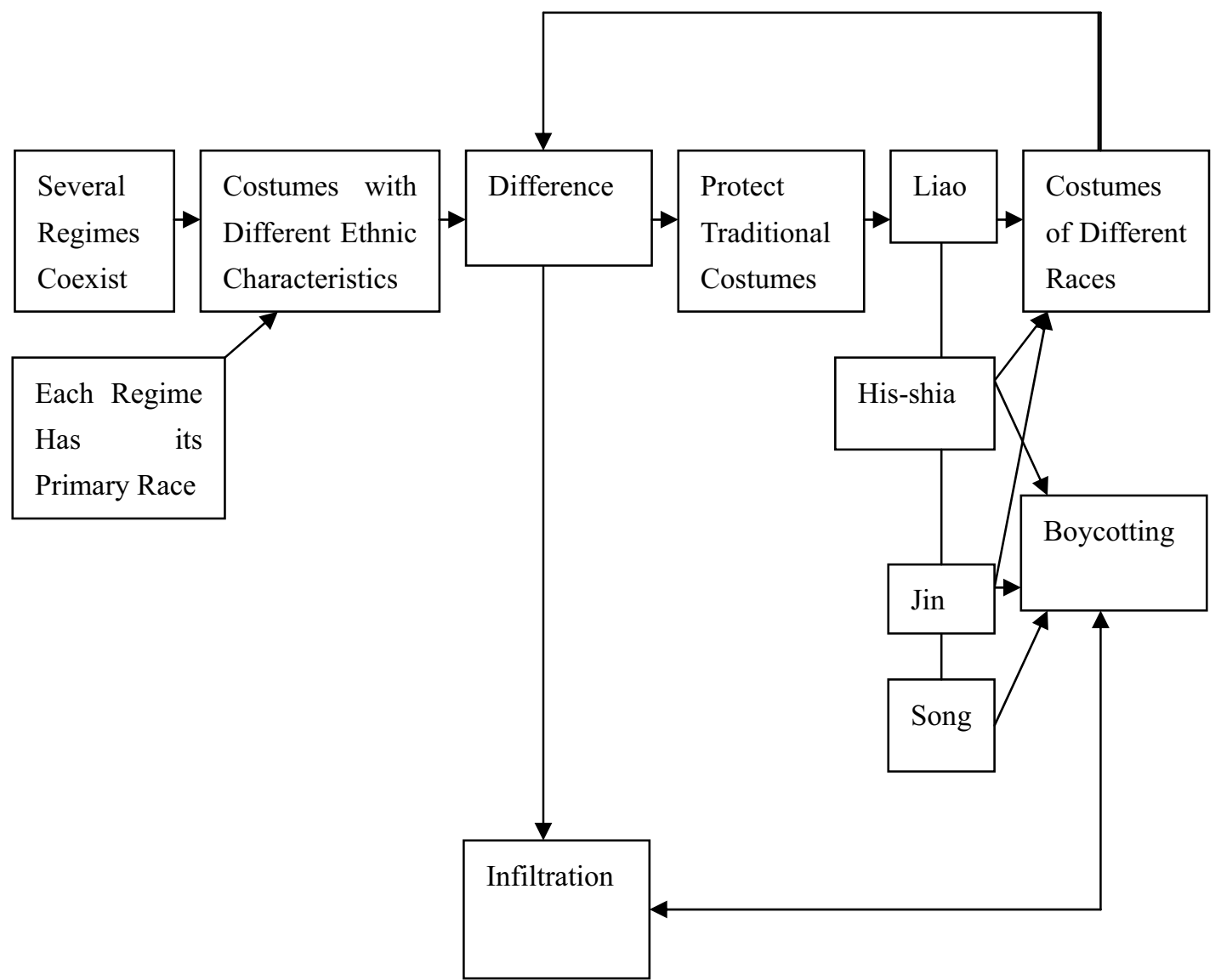

Several regimes coexisted during the Song period, except the Song state, other regimes were respectively installed primarily by a single minority, which resulted in each state having its own ethnic costumes. As the minorities got strong and their regimes became stable and gained an equal status with the Song sate, they began to learn highly developed culture and well-established ceremonial system from the Hans to establish their own system of costumes. Liao, His-shia and Jin were primarily set up by the Khitans, Tanguts and Jurchens, besides the Hans, there were other minorities under their reign, and therefore, it was reasonable for costumes of different races coexist under each regime.

On the other hand, in order to maintain its own characteristics of costumes each minority had taken various measures, even taken measures to resist the costumes of other races, especially the Hans. Song was established by the Hans, the Song government tried hard to maintain a appearance of orthodox in the condition of being weak militarily and buying peace with a large quantity of money, therefore it is understandable that Song took a firm stand on resisting the impact of the costumes of the minorities, let alone the costumes of the minorities, costumes similar to the costumes of the minorities was also forbidden. From the policies of resisting the costumes of other races, we learned political factors were of great influence, for maintaining stable or for fighting for power, etc.

Wars occasionally out broke between separatist regimes, however, compared with other periods of great division of China in history this period was considerably peaceful. Therefore, although there was boycotting, as time went by, little by little the costumes of different races reacted on each other, exchanges of costumes not only occurred between the minorities and the Hans but also among the minorities.

\section{References}

Bi, Yuan. (1957). Xu zi zhi tong jian (an continuation of the historical work History as a Mirror). Beijing: Classics Publishing House. vol.103.p.2709.

Herbert Franke and Denis Twitchett. (1998). The Cambridge History of China vol.6:Alien Regimes and Border States, 907-1368. Beijing: China's Social Sciences Publishing House. p228.

Ji, Nannan. (2006). Lun liao dai you yun shi liu zhou de han ren wen ti (research on the Hans lived in sixteen counties including You County and Yun County of the Liao Dynasty).Master's thesis. Northeast Normal University.

Li, Xinchuan. (1992). Jian yan yi lai xi nian yao lu I (records of the events since 1127). Shanghai Classics Publishing House, vol.28.p.432

Li, Zhiliang. (2005). Song shi quan wenIII (complete records the Song Dynasty), Heilongjiang People's Publishing 
House.vol.24.pp.1627-1664.

Liu, Xu. (1975). Jiu Tang Shu. Beijing: Zhong Hua Books Co.vol. 198. pp5290-5292.

Meng, Yuanlao and Deng, Zhicheng. (1982). Dong jing meng hua lu zhu (Materials about the capital of the Song Dynasty). Beijing: Zhong Hua Books Co.vol.7.P.196.

Shen, Congwen. (2005). Study of Chinese Ancient Costumes. Shanghai: Shanghai Bookstore Publishing House.(introduction). P.8.

Tuotuo. (1974). Liao ShiIII (History of the Liao Dynasty ). Beijing:Zhong Hua Books Co. pp.907-908.

Tuotuo. (1975). Jin ShiI shi zong zhuan (history of the Jin Dynasty: biography of Jin Shizong).Beijing:Zhong Hua Books Co.p.199

Tuotuo. (1975). Jin shilII (history of the Jin Dynasty ).Beijing:Zhong Hua Books Co.p.975

Tuotuo. (1977). Song Shi (history of the song dynasty). Beijing:Zhong Hua Books Co. vol.153. p.3575-3577

Wen, Lihe. (1989). Liao ning fa ku xian ye mao tai liao xiao yi mu (the tomb of Xiao Yi found in Yemaotai, Faku County, Liaoning dated to the Liao Dynasty). Archaeology, no.4, p.327.

Wu Guangcheng and Gong Shijun. (1995). .Xi xia shu shi jiao zheng(history of His-shia). Gansu Cultural Publishing House, vol.11.p.132

Wu, Zeng. (1979). Neng gai zhai man lu (events recorded by scholars of the Song Dynasty) .Shanghai: Shanghai Classics Publishing House .vol.13.p.387

Wu, Zeng. (1979). Neng gai zhai man lu (events recorded by scholars of the Song Dynasty) .Shanghai Shanghai Classics Publishing House. vol. 1. p.16

Xie, Jing. (2007). Dun huang shi ku zhong xi xia gong yang ren juan xian zhe fu shi yan jiu (a study of the costumes on the donors of His-shia depicted by the mural paintings in the Mogao Grottoes). Dunhuang Research. No.3. p26.

Yu, Hui. (1990). 'Jin dai ren ma hua kao lue ji qi ta : min zu xue, min su xue he lei xing xue zai gu hua jian ding zhong de zuo yong (study of the paintings of riders of the Jin Dynasty)'. Art Research, No.4, p.38.

Yuwenmaozhao. (1986). Da jin guo zhi jiao zheng (an revision of the records of the Jin Dynasty II). Beijing: Zhong Hua Books Co. p.552.

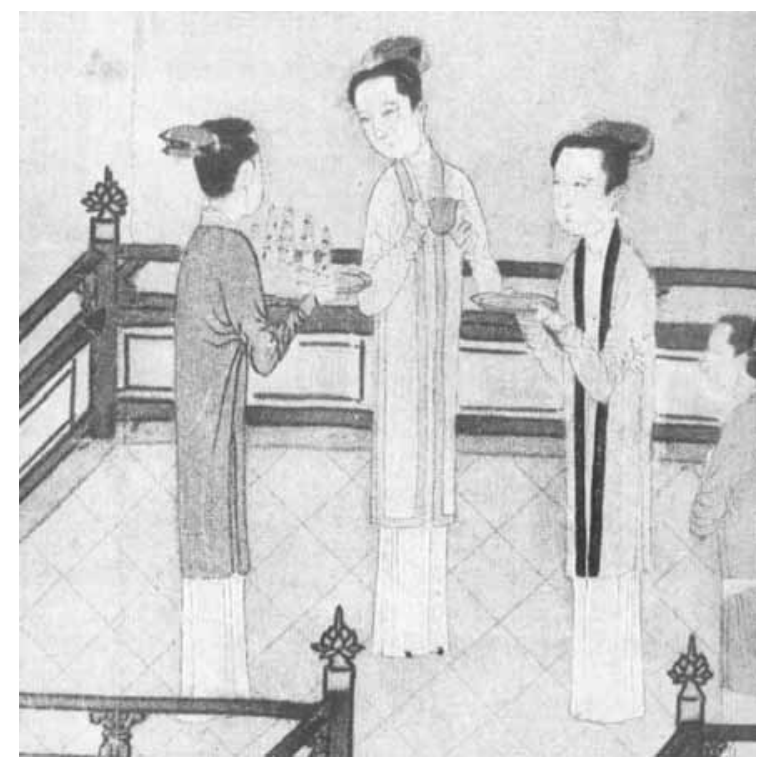

Figure 1. Part of a scroll 'painting Yao Tai Bu Yue'attributed to a Song painter 


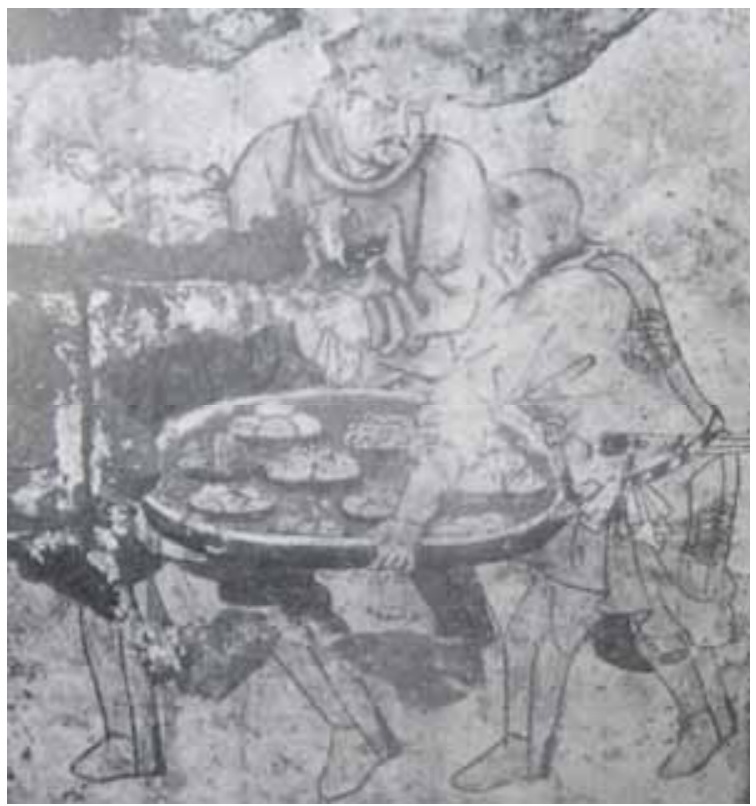

Figure 2. Drawing of a tomb mural from Dishuihu,Balinzuoqi,Inner Mongolia

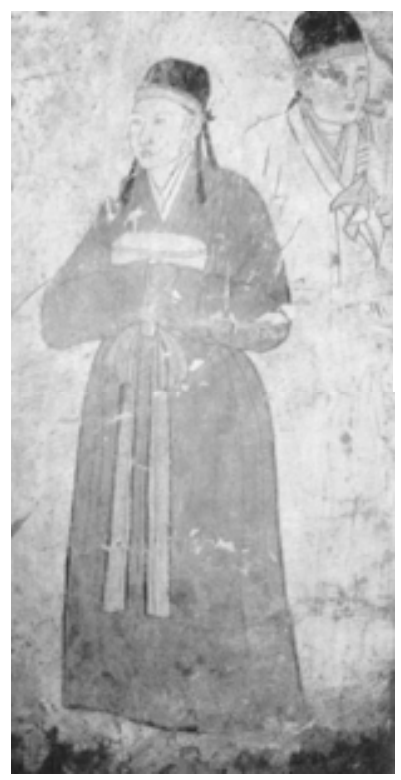

Figure 3. Mural Painting from Kulun Banner,Inner Mongolia

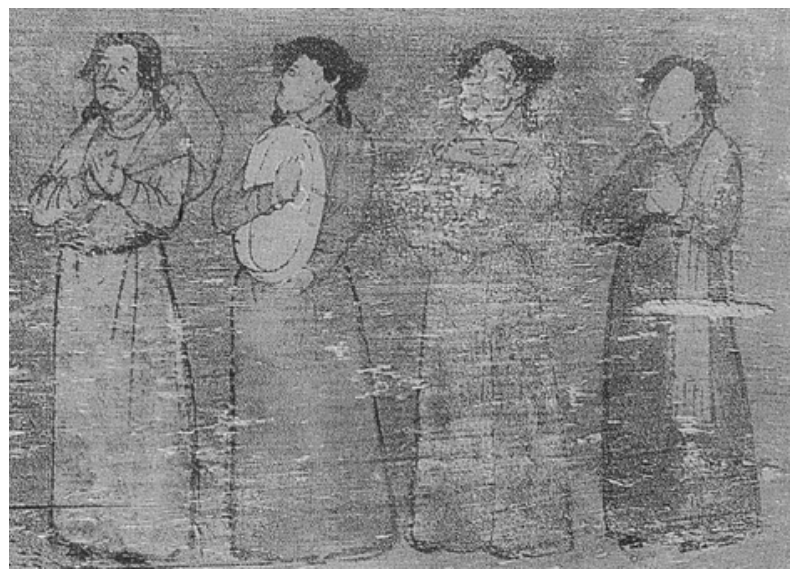

Figure 4. Part of a painting on the board,Wuwei,Gansu 


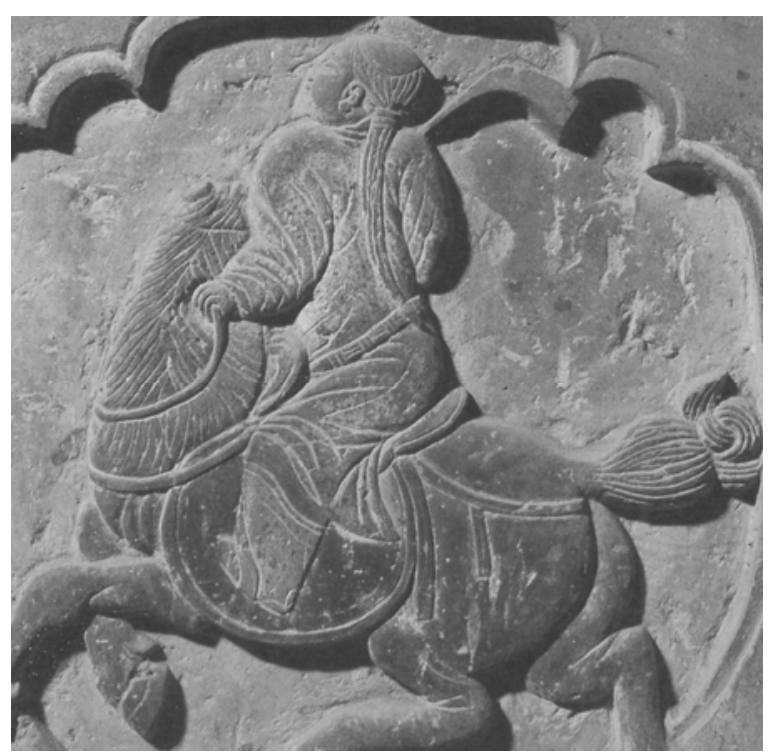

Figure 5. Tile carving from Dong Hai Tomb,Houma,Shanxi

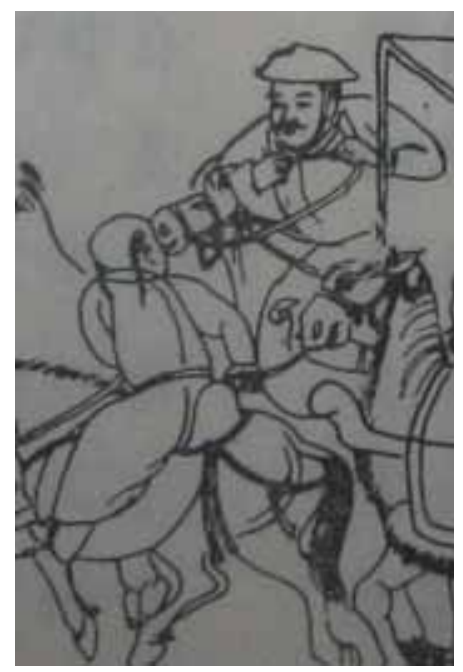

Figure 6. Part of the Study Sketch of mural painting from Xiao Yi Tomb, Yemaotai,Liaoning

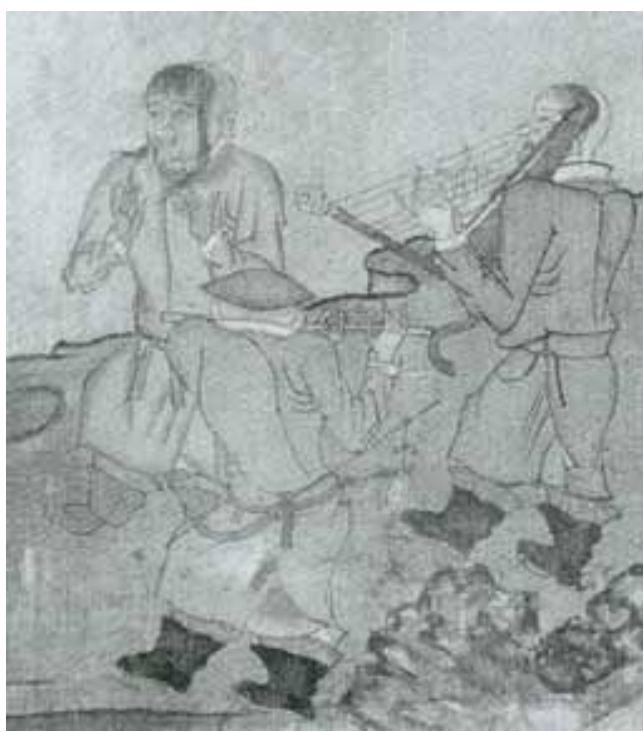

Figure 7. Part of a scroll painting 'Avalokitesvara' excavated from Heishuicheng, E’ji'naqi, Inner Mongolia 